\title{
PROGRAMA OBSERVATÓRIO DA EDUCAÇÃO: Possibilidades Para (Re)Pensar o Currículo de Matemática do Ensino Fundamental
}

\author{
Marli Teresinha Quartieri ${ }^{1}$, Bruna dos Santos², \\ leda Maria Giongo ${ }^{3}$, Márcia Jussara Hepp Rehfeldt ${ }^{4}$
}

\begin{abstract}
RESUMO
Este texto tem por objetivo socializar as percepções de um grupo de professores da Educação Básica no que se refere a um conjunto de ações desenvolvidas em uma pesquisa/intervenção vinculada ao Programa Observatório da Educação (Edital Inep/Capes 049/2012). A investigação, de cunho qualitativo, teve o intuito de elaborar e problematizar práticas pedagógicas que promovessem rupturas nos currículos escolares na disciplina de Matemática, em especial no Ensino Fundamental. O material de pesquisa consistiu em entrevistas semiestruturadas efetivadas com seis professores de escolas públicas que participaram do Programa, que também contava com a presença de pesquisadores, mestrandos e alunos de Graduação. Os relatos dos docentes entrevistados mostram que as discussões teórico-metodológicas e as atividades exploradas em encontros de estudos semanais possibilitaram reflexões e modificações nos currículos das escolas em relação aos conteúdos, metodologias e avaliação. Em particular, os entrevistados reforçaram que, por conta de sua participação, ocorreram significativas mudanças em suas práticas pedagógicas, em especial com a utilização de metodologias mais dinâmicas que possibilitaram aos alunos exercerem a proatividade.
\end{abstract}

Palavras-chave: Observatório de educação. Matemática. Ensino Fundamental. Reformulação curricular.

PROGRAM OBSERVATORY FOR EDUCATION: POSSIBILITIES FOR (RE)THINKING MATHEMATICS SYLLABUS IN PRIMARY SCHOOL

\begin{abstract}
This text aims at sharing perceptions of a group of teachers in Basic Education regarding a set of actions carried out in a research/intervention in the Program Observatory for Education (Inep/Capes notice 049/2012). This investigation is qualitative, and its purpose was designing and problematizing educational practices that promoted changes in Mathematics school syllabus, especially in Primary School. The research material consisted of semi-structured interviews carried out with six teachers of public schools participating in this Program; researchers, Master's degree students and undergraduate students also took part in it. The content of the teachers' interviews pointed to the fact that theoretical-methodological discussions and the activities performed in weekly study meetings enabled reflection and changes in the school syllabus regarding contents, methodologies and assessment. The interviewees specifically stated that, due to their participation, significant changes occurred in their educational practices, especially through more dynamic methodologies that made students proactive during classes. Keywords: Observatory for education. Mathematics. Primary school. Syllabus reformulation.
\end{abstract}

RECEBIDO EM: 10/7/2017

REVISÕES REQUERIDAS EM: 7/2/2018

ACEITO EM: 30/4/2018

\footnotetext{
${ }^{1}$ Graduação em Ciências (1987) e em Matemática (1989) pela Faculdade de Educação, Ciências e Letras do Alto Taquari. Especialização em Educação Matemática pela Universidade de Santa Cruz do Sul (1998). Mestrado em Matemática Aplicada pela Universidade Federal do Rio Grande do Sul (2004). Doutorado em Educação pela Universidade Vale do Rio dos Sinos - RS. Professora da Universidade do Vale do Taquari (Univates) nos cursos de Graduação e de Pós-Graduação (Mestrado em Ensino de Ciências Exatas e no Programa em Ensino). Bolsista de Produtividade em Pesquisa 2 do CNPq. https://lattes.cnpq.br/0483754754945290. Orcid: http://orcid.org/0000-0002-9621-3830. mtquartieri@univates.br

2 Orcid: https://orcid.org/0000-0003-1047-4413. bdsantos@universo.univates.br

${ }^{3}$ Graduação em Matemática (Furg). Especialização em Ensino de Matemática (Pontifícia Universidade Católica do Rio Grande do Sul - PUCRS). Mestrado e Doutorado em Educação (Universidade do Vale do Rio dos Sinos - Unisinos). Professora titular da Universidade do Vale do Taquari (Univates - Lajeado, RS), vinculada ao Centro de Ciências Exatas e Tecnológicas. Coordena o Grupo de Pesquisa Práticas, Ensino e Currículos (CNPq/Univates). É pesquisadora CNPq Nível 2. https://lattes.cnpq.br/2757706066808127. Orcid: https://orcid.org/0000-0002-1696-0642. igiongo@univates.br

${ }^{4}$ Graduação em Licenciatura em Ciências - Habilitação em Matemática (1985), Especialização em Educação Matemática (1997) e Gestão Universitária (2007), Mestrado em Administração (2001) e Doutorado em Informática na Educação (2009) pela Universidade Federal do Rio Grande do Sul. Professora titular na Universidade Vale do Taquari - Univates. Atua na formação de professores e integra o grupo de pesquisa Práticas, Ensino e Currículos e ocupa o cargo de coordenadora institucional da pesquisa. https://lattes.cnpq.br/4088071913818217. Orcid: http://orcid.org/0000-0002-0007-8639.mrehfeldt@univates.br
} 


\section{A TEMÁTICA E A CONDUÇÃO DA INVESTIGAÇÃO}

A Matemática, enquanto ciência, pode ser compreendida como uma forma de pensamento a ser desenvolvida nos sujeitos e sua linguagem e, segundo documentos oficiais, tem o intuito de organizar, interpretar e proporcionar significação aos aspectos da realidade. Pensando por esse viés, é importante ressaltar que a sociedade contemporânea tem determinado aos indivíduos, de forma crescente, reflexão e responsabilidade sobre as escolhas que realizam e as decisões que assumem. Neste sentido, a disciplina Matemática, num contexto em que se opera com tecnologias, passa a exercer uma função que se coloca para além da efetuação de operações. De acordo com Groenwald e Nunes (2007), é necessário estruturar o pensamento e construir tanto dados quanto informações para, assim, potencializar o conhecimento matemático.

De fato, o currículo de Matemática tem sido objeto de reflexão dos pesquisadores desta área na contemporaneidade, pois, a partir do momento em que passou a ser vista como uma ciência flexível que se aproxima do social, o currículo, do mesmo modo, necessita ser construído para alcançar tal finalidade. Nessa ótica, a proposta curricular é sustentada pela ideia de construir esse documento com embasamento teórico, aproximando as situações de aprendizagem com o contexto de cada aluno. Assim, devem ser considerados "os aspectos de funcionalidade dos conteúdos para os alunos, em que se proponham atividades didáticas que os levem a visualizar a aplicabilidade dos assuntos tratados [...]" (OLGIN; GROEWALD, 2013, p. 22). A proposta curricular consiste em não fazer o movimento de reduzir esse documento somente para medir competências e habilidades pois, de acordo com Urel e Pereira (2014), ao reelaborá-lo, deve-se ter o intento de colaborar com a reconstituição de pontos falhos que existem na Educação Básica. Ademais,

[...] a educação estimulada por uma construção curricular problematizadora deve ser coletiva, fundada em problemas e perguntas, entre as quais: $O$ que aprender? Como aprender? Por que aprender? Aprende-se individual ou coletivamente? 0 conhecimento é neutro? Quem deve escolher conteúdos pragmáticos, metodologias, comportamentos e procedimentos? O conhecimento dos alunos parte do currículo, é respeitado? Os diálogos de saberes serão validados? E a experimentação? E os livros didáticos: serão prescritos ou interativos e criativos; normativos e preconceituosos ou democráticos e éticos? (SCOCUGLIA, 2011, p. 107).

Ao refletirem sobre as questões propostas pelo referido autor e os objetivos a que se propõe a Matemática no ambiente escolar, os docentes precisam buscar metodologias que possibilitem ao aluno (re)significar o conteúdo. Essa relação poderá proporcionar a compreensão das regras matemáticas e também o desenvolvimento das capacidades intelectuais dos educandos.

Olgin e Groenwald (2013) argumentam que o currículo de Matemática do Ensino Fundamental está profundamente ligado a alguns princípios. Estes carregam reflexões importantes, como elaboração de atividades pedagógicas, por meio da qual o aluno tem a possibilidade de criar formas inventivas de resolução dos problemas matemáticos, bem como encontrar validade nas suas conjecturas, viabilizando a autonomia que o leve a identificar os caminhos para chegar a alguns resultados e, assim, torná-lo ativo no processo de ensino. Por fim, destaca-se a potencialidade do trabalho em grupo visto 
como uma maneira de proporcionar discussões acerca dos diversos destinos percorridos para se alcançar a resolução de problemas, desenvolvendo a formação escolar e social do estudante (OLGIN; GROENWALD, 2013).

Os Parâmetros Curriculares Nacionais (PCNs), na qualidade de instrumentos úteis no apoio às discussões curriculares e reflexões sobre a prática pedagógica nas escolas, constituíram-se em um referencial para a educação no Ensino Fundamental em todo o país. Esses documentos tinham o intuito de

[...] orientar e garantir a coerência dos investimentos no sistema educacional, socializando discussões, pesquisas e recomendações, subsidiando a participação de técnicos e professores brasileiros, principalmente daqueles que se encontram mais isolados, com menor contato com a produção pedagógica atual (BRASIL, 1997, p. 13).

Assim, as ideias expressas no referido documento ainda servem como base para a elaboração dos currículos nas escolas. Eles, por sua vez, têm a função de nortear os processos de ensino e aprendizagem, conectando-se, dessa forma, diretamente com a qualidade da educação.

Eles são traduzidos nos objetivos que se deseja atingir, nos conteúdos considerados os mais adequados para promovê-los, nas metodologias adotadas e nas formas de avaliar o trabalho desenvolvido. A definição de quais são esses conhecimentos e valores vem sendo modificada nos últimos anos, devido às demandas criadas pelas transformações na organização da produção e do trabalho e pela conjuntura de redemocratização do país. Portanto, a meta de melhoria da qualidade da educação impôs o enfrentamento da questão curricular como aquilo que deve nortear as ações das escolas, dando vida e significado ao seu projeto educativo (PRADO, 2000, p. 95).

Pensando na importância de se proporem estratégias possíveis para a reconfiguração curricular, o programa governamental Observatório de Educação, alocado numa Universidade gaúcha, está em fase final de desenvolvimento de uma pesquisa/intervenção no campo da Matemática com foco no Ensino Fundamental. Esta tem tido o intuito de repensar o currículo na área da Matemática tanto nos Anos Iniciais quanto nos Anos Finais do Ensino Fundamental. Tal iniciativa justificou-se pela necessidade de repensar o currículo da área da Matemática, uma vez que, nas aulas dessa disciplina, o professor vem tendo dificuldades em usar estratégias diferenciadas em sua prática pedagógica, bem como refletir sobre a aplicabilidade de alguns conteúdos.

O ensino da Matemática tem um papel de destaque nas escolas sendo muito valorizado tanto pelos saberes como pelas habilidades e competências que a mesma desenvolve nos alunos. Mas nem todos os conteúdos desta disciplina têm sido desenvolvidos com todo o potencial esperado, em especial aqueles vinculados à Geometria (SCHMITT, 2013, p. 3).

Para alcançar o objetivo do referido projeto, são realizadas, semanalmente, reuniões com alguns integrantes do Observatório, sendo estes docentes vinculados à Instituição (três da área da Matemática e um da Pedagogia), alunos do Mestrado Profissional em Ensino de Ciências Exatas, professoras de seis escolas públicas do Vale do Taquari, parceiras do projeto, alunos de Graduação e docentes voluntários que foram se 
agregando à equipe. Nesses encontros são discutidas e elaboradas, de forma conjunta, situações de aprendizagem, tendo por foco três tendências: Etnomatemática, Investigação Matemática e Modelagem Matemática.

Quanto à Investigação Matemática, o grupo estuda ideias vinculadas aos estudos de Ponte, Brocardo e Oliveira (2009). Para esses autores, em atividades investigativas (que são situações abertas, geralmente com mais de uma resposta) o discente age como um matemático na formulação e reformulação de conjecturas. Os autores alimentam a necessidade de que as atividades sejam desenvolvidas em pequenos grupos e os resultados socializados e discutidos com toda a turma. Além disso, os alunos desenvolvem a escrita, pois todas as respostas devem ser registradas.

No que se refere à Modelagem Matemática, o grupo segue os estudos de Burak e Aragão (2012). Nessa perspectiva, as atividades iniciam com a escolha do tema, que deve ser algo do interesse dos alunos. Ato contínuo, ocorre a pesquisa exploratória, cujo intuito é conhecer questões pertinentes ao tema escolhido. Já a terceira etapa é o levantamento do problema central a partir do qual são elencados as questões a serem modeladas. Por sua vez, a quarta etapa consiste na resolução desses problemas e no desenvolvimento do conteúdo matemático e, na última, é efetivada a análise crítica da solução dos problemas.

Na Etnomatemática, segundo D’Ambrósio (2013), procura-se compreender a história de diferentes povos, levando-se em consideração o interesse de diferentes grupos. Nesse contexto, Knijnik et al. (2012) salientam que esse campo tem uma abordagem abrangente, considerando outras formas como Etnomatemática, tais como a matemática presente em jogos infantis, a exercitada por mulheres e homens para suprir as suas necessidades de sobrevivência, entre outras.

Para compor teoria e prática, isto é, fazer junção entre as atividades de matemática e a fundamentação teórica, foram realizadas discussões a partir de leituras de textos que proporcionaram diferentes olhares para uma nova configuração curricular, bem como para a sociedade na qual o contexto escolar está inserido. O diferencial deste trabalho desenvolvido pelos componentes do Observatório de Educação, está em oportunizar aos docentes um espaço sistemático e contínuo no qual eles possam expor suas experiências de trabalho para dialogar com o ensino e a prática, potencializando o intercâmbio de ideias e propostas de atividades diferenciadas para se trabalhar a Matemática em sala de aula. Ademais, via inspiração em estudos de Nacarato (2016), realizam-se investigações "com a escola" em detrimento de análises "sobre" a escola e "na escola".

Por conta disso, as reuniões semanais são espaços de discussões teórico-metodológicas com vistas à reestruturação curricular no ensino da Matemática na escola Básica, com foco nas três tendências. Tais espaços abarcam professores da Escola Básica, pesquisadores e alunos de Graduação e de Pós-Graduação da Universidade, o que tem permitido troca de experiências alicerçadas no âmbito da docência com pesquisa. Nesta ótica, cada membro do grupo também apresenta aos demais suas investigações, com o intuito de socializar e contribuir para as discussões e a consequente melhoria nos processos de ensino e de aprendizagem desta disciplina. 
Outra ação efetivada pelo grupo tem sido a formação continuada nas escolas parceiras. Estas ocorrem via demanda dos educandários e com a participação de todos os integrantes do grupo de pesquisa. De posse de tais demandas, trazidas pelos seis professores representantes das escolas parceiras, o grupo inicia os estudos com a finalidade de construir tarefas a serem problematizadas com todos os docentes de Matemática e dos Anos Iniciais do Ensino Fundamental das escolas. Os encontros de formação são realizados nas dependências das escolas, em horário de reuniões pedagógicas previamente agendadas, e contam com a presença obrigatória do professor que acompanha as reuniões semanais. Nesses momentos, além das discussões referentes às três tendências foco de estudo, problematizam-se alguns conteúdos matemáticos, como frações e geometria, demandados pelos educandários. Salienta-se que as tarefas elaboradas pelo grupo são exploradas nos momentos de formação, pois todos os participantes as resolvem apresentando, inclusive, as estratégias usadas. Após, discute-se a sua viabilidade e sugerem-se adaptações para cada nível de ensino.

Destarte, este artigo tem como objetivo socializar os resultados decorrentes de entrevistas realizadas com as professoras parceiras do projeto. Por sua vez, a entrevista teve o intuito de verificar de que forma as ações promovidas pelo referido Observatório da Educação contribuíram para se (re)pensar o currículo, em particular no que diz respeito à disciplina de Matemática.

Optou-se, neste texto, por um recorte analítico baseado em entrevistas semiestruturadas aplicadas às participantes do projeto. Foram entrevistadas seis professoras, oriundas das seis escolas parceiras, ambas instituições da rede pública. Desse grupo, quatro possuem formação na área de Matemática, uma é graduada em Pedagogia e a outra tem formação em Ciências Biológicas. Destaca-se que duas vêm atuando como professora dos Anos Iniciais, três nos Anos Finais, e, no Ensino Médio, como professora de Matemática, uma, como coordenadora pedagógica de uma das escolas.

Um roteiro semiestruturado, com perguntas abertas embasadas no tema a ser investigado, foi realizado. As indagações foram focadas em seis pontos, assim descritos: Quais os conteúdos que costumas trabalhar com sua turma? Poderias citar outros conteúdos que são trabalhados no Ensino Fundamental? Quais os motivos pelos quais escolhestes estes conteúdos em detrimento de outros? Quais os conteúdos que consideras mais importante trabalhar? Quais as metodologias que frequentemente utilizas em sala de aula? De que forma tua participação no Observatório permitiu compreender ou alterar o cenário em que trabalhas?

Tais indagações tiveram a função de oferecer uma direção para a entrevista, ou seja, possibilitar às educadoras acessarem problemáticas escolares que, de algum modo, proporcionassem sentido aos seus discursos com relação às experiências diárias referentes à prática educacional e ao currículo de Matemática. Sob esse prisma, foram questionadas quanto aos conteúdos matemáticos trabalhados (como ocorreu a escolha e a importância), à metodologia usada no decorrer da sala de aula, à forma de avaliação, às mudanças curriculares (se ocorreram ou não, com justificativa) e às contribuições das ações desenvolvidas no Observatório da Educação na prática pedagógica. 
Cada professora foi entrevistada, individualmente, em média, durante 30 minutos, fazendo-se uso de um gravador para que a conversa ficasse registrada. As participantes foram informadas dos procedimentos da enquete e suas enunciações foram, transcritas e, posteriormente, analisadas. A metodologia utilizada baseou-se na busca de elementos comuns nos depoimentos das docentes de modo a estabelecer aproximações entre as percepções que emergiram.

Por conta disso, trata-se de uma pesquisa qualitativa, pois, no âmbito da educação/ensino, pesquisadores frequentemente têm feito uso desta metodologia, tendo em vista que, como bem aponta Bezerra (2010), tal abordagem permite que o pesquisador esteja em contato com o contexto em que os pesquisados estão inseridos. A esse respeito, Angrosino (2009, p. 8) explicita que a abordagem qualitativa "visa a abordar o mundo 'lá fora' [...] e entender, descrever e, às vezes, explicar os fenômenos sociais 'de dentro'" [...] "a forma como as pessoas constroem o mundo à sua volta, o que estão fazendo ou o que está lhes acontecendo em termos que tenham sentido e que ofereçam uma visão rica" (p. 8).

Neste mesmo referencial, D’Ambrósio e D’Ambrósio (2006, p. 77-78) aludem que esta é "a mais adequada para pesquisa em educação", pois procura "entender e interpretar dados e discurso, mesmo quando envolve grupos de participantes" (Ibidem, p. 78).

\section{O QUE DIZEM AS PROFESSORAS}

Esta seção propõe-se a socializar os resultados da pesquisa, articulada a uma discussão teórica que esteja entrelaçada ao discurso das professoras com relação às ações promovidas pelo Observatório. A partir das enunciações, compreendeu-se que o trabaIho desenvolvido exerceu um papel fundamental nas ações dessas profissionais, principalmente no movimento que efetivaram para repensar a forma de ministrar aulas e no refletir sobre como potencializar o uso de metodologias diferenciadas que pudessem ampliar a forma de trabalharem com a Matemática. Nesse sentido, assim apontou uma das professoras ${ }^{5}$,

Influenciou bastante. Agregou muito com relação à parte das atividades que eu levo para a sala de aula. A gente consegue ser mais criativo e consegue trabalhar a matemática de uma forma não sistemática. Então a gente leva atividades diferentes; claro que tem a ver com minha formação também na minha vida de faculdade, mas eu aprofundei mais. A gente cada vez mais busca meios de facilitar a compreensão dos alunos, de que eles não vejam a matemática de uma forma difícil e sim prazerosa (P1).

Esse discurso vincula-se à ideia de um ensino que busca fazer com que o aluno construa seu conhecimento. Conforme Pozo e Crespo (1998), aprender e lecionar estão para além do processo de repetição e armazenamento de conhecimentos. Os autores também alertam que o que está em jogo é a implicação e transformação da construção de pensamento de quem aprende, uma vez que o sujeito, para aprender, precisa apropriar-se das significações que possui cada conteúdo.

\footnotetext{
${ }^{5}$ Com o intuito de preservar o anonimato das entrevistas, as professoras serão denominadas por P1, P2, P3, P4, P5 e P6.
} 
A Matemática, assim como a ciência que trabalha a abstração, acaba estudando o mundo por meio de modelos existentes de uma forma abstrata. Faz-se necessário, portanto, investir em atividades que propiciam o desenvolvimento desse raciocínio (GROENWALD; NUNES, 2007). O nível de abstração, de acordo com os autores, deve permitir que o sujeito consiga se relacionar com o conhecimento a priori adquirido, exigindo ações para além da memorização, isto é, desenvolvendo a capacidade de aplicar os conhecimentos em situações diversas.

Destaca-se, nas enunciações analisadas, que um dos conteúdos citados como ponto forte de mudanças nos currículos de Matemática foi a inclusão da Geometria. Nos depoimentos, evidencia-se que esse conteúdo era pouco ensinado e, após as reflexões durante os encontros sistemáticos com o grupo de professores do Observatório, mereceu um olhar mais atento por parte das docentes das escolas parceiras. $O$ fato é que, ao ser compreendida pelas professoras, a Geometria passou a ser desenvolvida de forma mais dinâmica e próxima do contexto dos alunos.

Para mim está ajudando bastante na parte da matemática. Modifiquei bastante, comecei a entender maneiras diferenciadas de se trabalhar. Por exemplo, a geometria para mim era sempre mais difícil. Eu não chegava muito na geometria. Agora trabaIhei a geometria esse ano, com os blocos lógicos. Eles aprenderam facilmente, pegaram o conteúdo, entenderam e aprenderam facilmente, porque a gente viu maneiras diferentes para se trabalhar. Portanto, estes encontros estão ajudando muito. Foi fantástico, deu resultado que eu não imaginava que desse. Muito bom (P3).

A Geometria é considerada por Rogenski e Pedroso (2007) uma ponte que conecta diversos conteúdos. Para os autores, é repleta de elementos que facilitam a aprendizagem de álgebra e números. Ademais, trabalha com formas e medições, favorecendo o desenvolvimento da percepção parcial, bem como a linguagem e o raciocínio geométrico por meio da construção de significações.

Conforme os PCNs (BRASIL, 1997), o ensino da geometria tem o papel de desenvolver no aluno a percepção de si e do espaço por intermédio de elementos da natureza e objetos criados pelo homem. Isso pode ocorrer por meio da exploração de objetos, como mosaicos, flores, arquitetura e outros. Em relação ao trabalho com a geometria, uma das professoras parceiras destaca que é possível entrelaçar os conteúdos geométricos com outros e isso proporciona ao discente ampliar seus conhecimentos. Para a referida docente, o ensino deste ramo da Matemática falha por se limitar aos cálculos e resolução de problemas. Esse é um ponto importante para se (re)pensar as dificuldades nessa disciplina.

Como eu falei antes, a questão da geometria. Eu vejo a geometria, assim, muito importante para se trabalhar na questão de ampliar os conhecimentos. Então dentro da geometria tu podes trabalhar vários outros conteúdos, que tu podes lincar com outros conceitos. Por exemplo, quando se trabalha com monômio ou polinômio, a gente pode trabalhar com fatoração, com atividade com quadrados, retângulos. Podemos lincar, trabalhando perímetro, também isso é geometria e não deixa de ser um monômio e um polinômio. Então eu acho que, nessa parte, a gente falha um pouco, a gente como escola não se aprofunda tanto nisso. A matemática é trabalhada de uma forma muito sistemática vamos dizer assim, apenas cálculos e resoluções. Não se deixa muito o aluno pensar (P2). 
Rogenski e Pedroso (2007), por sua vez, possuem uma visão acerca das dificuldades dos alunos na disciplina de Geometria. Nesse sentido, eles apregoam que um dos elementos que contribuem para os problemas enfrentados pelos discentes é a defasagem que existe no Ensino Fundamental, pois o estudo desse ramo da Matemática nem sempre é relacionado com outros conteúdos que, de certo modo, são estruturantes. Os autores ainda pontuam que essa dificuldade também se encontra na figura do professor, motivo pelo qual a Geometria acaba sendo pouco problematizada na disciplina de Matemática.

Rogenski e Pedroso (2007) salientam que a utilização de materiais manipuláveis é importante no ensino de Geometria, pois eles auxiliam na construção de uma imagem mental representativa pelos discentes sobre os conteúdos geométricos. Essa forma pode facilitar o desenvolvimento do raciocínio visual nas situações em que há a ausência de um objeto que permite a construção de um esboço gráfico.

A gente começa trabalhando uma atividade prática, muitas vezes com material concreto, coisas que eles conseguem fazer, pois o manuseio é de mais fácil memorização (P5).

Para que o conteúdo de Geometria ensinado produza sentido e tenha significado para o aluno, percebeu-se, no grupo entrevistado, que é relevante considerar a interação do sujeito com o objeto por meio do manuseio. Nesse sentido, a Base Nacional Curricular Comum (BNCC) destaca que "desde a Educação Infantil, os/as estudantes tomam contato com a Geometria, seja em atividades escolares, seja por meio da observação do espaço que os cerca" (BRASIL, 2016, p. 255). Em relação à importância de trabalhar com conteúdos de Geometria desde a Educação infantil, os PCNs (BRASIL, 1997) também já preconizavam que esse campo da Matemática é amplo, podendo ser contemplado em sala de aula por meio de problemas matemáticos, além de ser um conteúdo pelo qual os discentes se interessam. Trabalhar com noções de Geometria contribui para a aprendizagem de conteúdos que envolvem números e medidas, pois estimula a criança a raciocinar, diagnosticar semelhanças e diferenças e compreender relações e regularidades.

Quanto às frações, percebeu-se, nos depoimentos analisados, que as professoras também apresentavam dificuldades ao tratarem esses números. Segundo uma delas, os problemas têm surgido na hora em que ministravam os conteúdos em sala de aula. É nessa relação professor-aluno que a dificuldade surge, podendo ocasionar um declínio na aprendizagem.

[...] trabalhar com frações porque quando eles se deparam com as frações desses números decimais, aí eles dão uma travada. [...] Muitos professores, às vezes não gostam de trabalhar, sentem a dificuldade que o aluno tem e vão passando adiante. $\mathrm{E}$ o aluno não entende o que ele faz. No momento que ele não entende o que ele faz, ele não vai aprender. [...] Nesse ponto, o Observatório auxiliou para o ensino de frações, pois trabalhamos com atividades dinâmicas e concretas. Também ajudou a observar melhor as coisas, a observar mais como posso trabalhar, como eu posso "cobrar" [referindo-se à avaliação] do aluno (P6). 
O depoimento de P6 comprova que os professores, ao apresentarem dificuldades nesse conteúdo, acabam discutindo-o rapidamente com seus alunos, sem que estes tenham entendido o que ocorre durante o uso de tal campo numérico. A definição de frações configura-se como a representação de "elementos que não são tomados como partes inteiras de alguma coisa; utilizamos o objeto matemático denominado fração" (CAVALIERI, 2005, p. 20). O autor prossegue assinalando que os números racionais não negativos são titulados de frações, e os números inteiros, quando utilizados em contas fracionárias, são nomeados de numerador e denominador, sendo estes separados por uma linha horizontal. Segundo ele,

O importante, no estudo de frações, como, aliás, de toda a matemática não é enviar a todo custo a memorização de definições e regras, sem compreensão, é possibilitar um aprendizado mais saudável onde o aluno possa participar de todo o processo de aquisição de conhecimento, consciente do que está aprendendo e compreendendo o conteúdo, não simplesmente decorando e não conseguindo assimilar nada do que está sendo ensinado (p. 9-10).

A construção dos conceitos que utilizam os números racionais segundo os PCNs (BRASIL, 1997, p. 69), "será iniciado no segundo ciclo do ensino fundamental e consolidado nos dois ciclos finais". Ainda conforme os PCNs, a Matemática no segundo ciclo tem objetivos para com o ensino das frações e, neste sentido, é importante que o aluno consiga fazer uma construção da significação do número racional bem como do decimal. Por meio dessa significação do conteúdo, espera-se que o discente utilize esse conhecimento para produzir estratégias de resolução por meio da seleção de procedimento de cálculos, criando hipóteses e chegando em várias conjecturas possíveis.

De acordo com os referidos parâmetros, o uso das frações na vida cotidiana limita-se a metades, terços, quartos e está relacionado mais à parte oral do que no plano das significações. Por isso, é interessante operar esse conteúdo em quatro formas, sendo elas: relação parte e todo, na qual um todo se divide em partes; quociente, quando se divide um número natural por outro; interpretada como razão, a fração é utilizada como comparativo entre dois números de uma grandeza; e a última forma de trabalho desse conteúdo é da fração como um operador, em que sua função é desempenhar um papel numa situação de modificação (BRASIL, 1997). De acordo com uma das professoras entrevistadas, é necessário que o aluno aprenda frações para que, posteriormente, construa e entenda outros conteúdos.

[...] frações ... geometria, frações e trabalhos com números decimais, porque tudo que envolve qualquer coisa matemática, envolve essa parte. Na geometria, tu usa os números decimais, usa frações, pode usar ... aplicar em outras coisas, conteúdos da trigonometria, do cálculo de área (P5).

Com relação ao trabalho que vem sendo desenvolvido pelo grupo proponente do Observatório por meio de estratégias diferenciadas para o ensino de frações, as entrevistadas pontuaram que, por meio dessas metodologias, o conteúdo fracionário, tanto dos Anos Iniciais quanto dos Anos Finais, começou a ser visto de forma mais simples e explorado com o uso de materiais concretos e situações-problema. Uma das professo- 
ras comentou: "Percebi que meus colegas, em particular, dos Anos Iniciais, não tinham mais tanta insegurança para trabalhar as frações. Além disso, o uso do material concreto era perceptível nas aulas dos mesmos" (P4).

Em relação às três tendências - Etnomatemática, Investigação Matemática e Modelagem Matemática -, as professoras foram enfáticas ao comentar que este trabalho está sendo produtivo e tem auxiliado na aprendizagem dos discentes:

O que nós estamos fazendo na Escola é como aqui no Observatório. Estamos trabaIhando em grupo as metodologias, tanto da Investigação quanto da Etnomatemática, como também da modelagem. Nosso objetivo é fazer com que o aluno consiga construir a partir daquele conhecimento que ele já tem, porque ele já traz uma bagagem de coisas que ele vê no dia a dia que ele estuda, que ele lê e que também a internet vem a favorecer (P1).

Pelo depoimento de P1, evidencia-se que as participantes, paulatinamente, incluíam as tendências problematizadas em suas aulas. Ademais, ocorria a valorização dos saberes dos alunos (tanto os da escola quanto os criados fora desse ambiente). Trabalhar a Matemática por meio do social, quando várias culturas são construídas, está sendo (re)pensado por alguns professores.

Acredito que a interpretação da atividade matemática faz com que desenvolva mais o raciocínio, o senso crítico, e também a questão financeira, o dinheiro, o dia a dia dos alunos faz com que eles tenham uma visão diferenciada da matemática (P3).

Durante as discussões nas reuniões, incentivou-se a realização de atividades com os professores e com os alunos com o propósito de articular os saberes e as culturas no processo de aprendizagem de Matemática. Salienta-se que isso ocorreu em razão da crença do grupo da necessidade de o conhecimento deixar de ser meramente transmitido de forma sistemática, passando a ser realizado por meio de trocas estabelecidas dentro e fora da sala de aula. Neste sentido, o currículo deixa de ser um documento similar a um índice de livros, uma vez que passa a ser flexível ao possibilitar que os conteúdos sejam imbricados com o contexto da escola e dos discentes.

Então, acredito que, independente da metodologia, da tendência trabalhada, o trabalhar em conjunto o aceitar a opinião, o caminho diferenciado para ser trabalhado a matemática vem trazendo um sucesso e vem trazendo resultados positivos (P4).

Nas práticas elaboradas e problematizadas no Observatório, teve-se o propósito de possibilitar ao professor desempenhar o papel de mediador nos processos de aprendizagem do aluno. Dessa forma, permitiria que este se colocasse de maneira ativa e inquiridora em sua aprendizagem, possibilitando a construção de diferentes conjecturas e estratégias de resolução.

Para os matemáticos profissionais, investigar é descobrir relações entre objectos matemáticos conhecidos ou entre estes e novos objectos matemáticos, procurando identificar e comprovar as respectivas propriedades (PONTE, 2008, p. 4). 
Neste contexto, é importante potencializar uma inter-relação entre o sujeito e o objeto, em que o aluno terá o papel de construir o conhecimento e, ao mesmo tempo, ser por ele construído por meio da sua relação com objetos que proporcionam a significação da aprendizagem matemática (PEREIRA, 2011). Cabe destacar, entretanto, que, ao modificarmos a proposta curricular, incluindo metodologias que objetivam tornar 0 discente ativo do seu processo de aprendizagem, também se deve modificar a forma de avaliá-lo.

Uma das entrevistadas destaca que o importante para a aprendizagem do aluno é a construção que ele faz no dia a dia, permitindo, dessa forma, que a avaliação seja um processo flexível e diário. Sendo assim, o estudante passa a ser avaliado não apenas individualmente, mas mediante a construção do conhecimento que se estabelece nas trocas em grupo, nos exercícios dinâmicos e diários que o docente promove e no crescimento do discente enquanto pesquisador e cidadão.

Acredito que um aluno, ele tem que ser avaliado não só na prova, numa avaliação, mas em todo o raciocínio, em toda a construção que ele faz no seu dia a dia, porque nós podemos e temos que ser avaliados, todo o dia, dia a dia. E essa avaliação, muitas vezes, ela se torna rotineira quando é fixado um dia estabelecido para medir os conhecimentos. E ela pode ser feita de uma maneira individual como também de grande grupo de forma oral, ou até mesmo através de uma atividade ou de um exercício feito construído no quadro ou através de um desenho ou através da montagem de um móbile, ou até mesmo através de uma medição. Então a avaliação, ela pode ser feita de qualquer maneira, basta ver que tenha o crescimento do aluno, como ser, como pessoa e também do grande grupo (P1).

Assim, a discussão conceitual e metodológica perpassou também a avaliação, conforme observado no comentário da professora P1. Salienta-se a importância da discussão da avaliação quando se tem o intuito de realizar uma reforma curricular. Não basta modificar conteúdo e usar metodologias diferenciadas se o processo de avaliação não sofrer mudanças de acordo com tais metodologias. Ademais, entende-se a necessidade de que a avaliação seja algo contínuo e processual, não somente vinculada a uma ou duas notas no final de um período letivo. Esses debates perpassaram os momentos de formação e percebeu-se certa "fragilidade" quanto a esse tema e sua forma de inserção nos currículos. Sendo assim, como ação futura, o grupo pretende dedicar-se a estudos e investigações que o envolvem na e para a disciplina de Matemática, em particular no Ensino Fundamental.

\section{ALGUMAS CONSIDERAÇÕES}

Mesmo que o currículo escolar, em muitas Instituições, ainda esteja sendo elaborado por meio de uma lista de conteúdos que se assemelham a um índice de livro, as professoras parceiras do projeto ressaltaram que o diferencial, ou seja, a mudança curricular, se inicia nas ações diferenciadas, embasadas nas tendências matemáticas que elas vêm realizando no seu contexto de trabalho. Nesse sentido, evidenciaram que o professor precisa entender o que está ensinando para que o aluno possa aprender o conteúdo de forma mais significativa. 
Quanto aos conteúdos observou-se que as experiências proporcionadas pelo Observatório estão sendo produtivas para os professores (re)pensarem o ensino de alguns conteúdos matemáticos. Temas que antes não eram discutidos, a partir da inserção do grupo de pesquisadores, foram explorados em sala de aula. Nesse contexto, destaca-se a Geometria, que passou a ser problematizada com os alunos não apenas no último semestre, mas nos períodos anteriores a ele.

Em relação às frações, as entrevistadas foram enfáticas ao comentar que tal conteúdo está sendo repensado principalmente nos Anos Iniciais. O fato é que os professores desse nível de ensino têm apresentado muitas dificuldades em relação a esse campo da Matemática. A partir do momento em que as dúvidas foram sendo sanadas, abriram-se possibilidades de os docentes refletirem sobre a aplicabilidade desses conteúdos matemáticos bem como planejar formas diferentes de ensiná-los.

As ações do referido Observatório da Educação tinham como propósito a reformulação curricular com o intuito de colocar o professor no papel de mediador e o aluno como coautor da sua aprendizagem. De acordo com os depoimentos das seis professoras das escolas parceiras, pode-se inferir que o propósito foi atingido em parte. As entrevistadas salientaram que, após a intervenção dos pesquisadores nas Escolas, os docentes estavam (re)pensando o currículo no que se refere aos conteúdos explorados, às metodologias utilizadas e à forma de avaliação. Além disso, explicitaram haver a necessidade de mais momentos de problematização, mas que a "semente foi plantada" nas Escolas, o que requer a continuidade do desenvolvimento de tais ações. Espera-se, neste contexto, que as professoras da Escola Básica, que participaram das ações efetivadas pelo referido Observatório da Educação, se sintam preparadas para, paulatinamente, "ousar" em suas práticas pedagógicas, fazendo com que se produzam rupturas e modificações no currículo escolar, em particular na disciplina de Matemática.

Tal "ousadia", entretanto, poderá ser potencializada com a permanência das docentes - e a inserção de outros/as - em projetos como os do Observatório da Educação. O fato de os professores da Escola Básica participarem de investigações geradas nas Instituições de Ensino Superior, por um lado, certamente Ihes proporcionará, em companhia com os pares, adensamento teórico-metodológico para promover rupturas nos processos de ensino e aprendizagem na disciplina Matemática; por outro, as universidades e seus pesquisadores também terão ganhos substanciais no que se refere a sua inserção na Escola Básica com um lócus privilegiado.

Logo, não parece ser mais admissível pensar em investigações na escola ocupando-se apenas em mostrar fragilidades e a potencialidade de outros modos de ensinar e aprender em tempos pós-modernos. Há que se pensar em investigações em que a Universidade e a Escola Básica sejam parceiras, balizadas por políticas públicas que promovam a integração entre os professores, pesquisadores, alunos de Graduação e Pós-Graduação, a exemplo do que foi possível por meio do Programa Observatório da Educação.

\section{REFERÊNCIAS}

ANGROSINO, Michael. Etnografia e observação participante. Porto Alegre: Artmed, 2009.

BEZERRA, Ada K. G. A pesquisa etnográfica e as especificidades da observação participante. Vinheta, Paraíba, v. 1, p. 1-18, 2010. Disponível em: http://www.fiponline.com.br/eventos/vinheta/textos/pesquisa\%20etnografica.pdf. 
BRASIL. Secretaria de Educação Fundamental. Parâmetros curriculares nacionais: matemática. Brasília: MEC; SEF, 1997. 142p.

BRASIL. Base Nacional Comum Curricular. 2016. Disponível em: http://basenacionalcomum.mec.gov.br/ documentos/bncc-2versao.revista.pdf. Acesso em: 15 abr. 2017.

BURAK, D.; ARAGÃO, R. M. R. A modelagem matemática e relações com a aprendizagem significativa. 1. ed. Curitiba: Editora CRV, 2012.

CAVALIERI, L. O ensino das frações. 2005. Monografia (Especialização em Ensino da Matemática) - Universidade Paranaense - Unipar -, Umuarama, 2005.

D’ AMBRÓSIO, Beatriz S.; D’ AMBRÓSIO, Ubiratan. Formação de professores de Matemática: professor-pesquisador. Atos de Pesquisa em Educação, Blumenau, v. 1, n. 1, p. 75-85, jan./abr. 2006.

D’AMBRÓSIO, U. Etnomatemática: o elo entre as tradições e a modernidade. 5. ed. Belo Horizonte: Autêntica Editora, 2013.

GROENWALD, C. L. O.; NUNES, G. da S. Currículo de matemática no ensino básico: a importância do desenvolvimento dos pensamentos de alto nível. Relime, México, v. 10, n. 1, p. 97-116, mar. 2007.

KNIJNIK, G. et al. Etnomatemática em movimento. Belo Horizonte: Autêntica, 2012.

NACARATO, Adair. A parceria universidade - escola: utopia ou possibilidade de formação continuada no âmbito das políticas públicas? Revista Brasileira de Educação, v. 21 n. 66. jul./set. 2016. Disponível em: http://www.scielo.br/pdf/rbedu/v21n66/1413-2478-rbedu-21-66-0699.pdf. Acesso em: jan. 2018.

OLGIN, C. de A.; GROENWALD, C. L. O. Criptografia: um tema de interesse para o Currículo de Matemática no Ensino Fundamental. In: GROENWALD, Claudia Lisete Oliveira; SILVA, Marcio Antonio da. Educação Matemática: contribuições para as Séries Finais do Ensino Fundamental e Médio. Canoas: Ed. Ulbra, 2013.

PEREIRA, M. Z. da C. Currículo e autopoiése: a produção do conhecimento. In: PEREIRA, Maria Zuleide da Costa; GONSALVES, Elisa Pereira; CARVALHO, Maria Eulina Pessoa de. Currículo e contemporaneidade. Questões emergentes. Campinas, São Paulo: Alínea, 2011.

PONTE, J. P. da. A investigação em educação matemática em Portugal: realizações e perspectivas. In: Investigar em Educação, vol. 2, p. 93-169, 2008.

PONTE, J. P. da; BROCARDO, J.; OLIVEIRA, H. Investigações matemáticas na sala de aula. Belo Horizonte: Autêntica, 2009.

POZO, J. I. M.; CRESPO, M. A. G. Aprender y enseñar ciencia: del conocimiento cotidiano al conocimiento científico. Madrid, España: Morata, 1998.

PRADO, I. G. A. O MEC e a reorganização curricular. São Paulo Perspectivas, São Paulo, v. 14, n. 1, p. 94-97, mar. 2000. Disponível em: http://www.scielo.br/scielo.php?script=sci_arttext\&pi$\mathrm{d}=$ S0102-88392000000100011\&lng=en\&nrm=iso.

ROGENSKI, M. L. C.; PEDROSO, S. M. D. O ensino da geometria na educação básica: realidade e possibilidades. 2007. Disponível em: http://www.diaadiaeducacao.pr.gov.br/portals/pde/arquivos/44-4.pdf. Acesso em: abr. 2016.

SCHMITT, F. E. Abordando geometria por meio da investigação matemática: um comparativo entre o 5ํ e 9o anos do Ensino Fundamental. 2013. Dissertação (Mestrado em Educação) - Programa de Pós-Graduação em Ensino de Ciências Exatas, Centro Universitário Univates, Lajeado, 2013.

SCOCUGLIA, A. C. Paulo Freire: conhecimento, aprendizagem e currículo. In: PEREIRA, Maria Zuleide da Costa; GONSALVES, Elisa Pereira; CARVALHO, Maria Eulina Pessoa de. Currículo e contemporaneidade: questões emergentes. 2. ed. Campinas, SP: Editora, Alínea, 2011.

UREL, A. L. J.; PEREIRA, A. da S. O discurso sobre "qualidade da educação" e a lógica das metas de desempenho: a qualidade como índice. Criar Educação. Santa Catarina: Unesc, v. 2. n. 2, p. 1-19, 2013. 